\title{
TOOLS FOR RECORDING PROTOTYPING ACTIVITIES AND QUANTIFYING CORRESPONDING DOCUMENTATION IN THE EARLY STAGES OF PRODUCT DEVELOPMENT
}

\author{
Soomro, Sohail Ahmed (1,2); \\ Barhoush, Yazan A M (1); \\ Gong, Zhengya (1); \\ Kostakos, Panos (1); \\ Georgiev, Georgi V. (1) \\ 1: Center for Ubiquitous Computing, University of Oulu, Finland; \\ 2: Sukkur IBA University, Pakistan
}

\begin{abstract}
Prototyping is an essential activity in the early stages of product development. This activity can provide insight into the learning process that takes place during the implementation of an idea. It can also help to improve the design of a product. This information and the process are useful in design education as they can be used to enhance students' ability to prototype their ideas and develop creative solutions. To observe the activity of prototype development, we conducted a study on students participating in a 7-week course: Principles of Digital Fabrication. During the course, eight teams made prototypes and shared their weekly developments via internet blog posts. The posts contained prototype pictures, descriptions of their ideas, and reflections on activities. The blog documentation of the prototypes developed by the students was done without the researchers' intervention, providing essential data or research. Based on a review of other methods of capturing the prototype development process, we compare existing documentation tools with the method used in the case study and outline the practices and tools related to the effective documentation of prototyping activity.
\end{abstract}

Keywords: New product development, Digital Fabrication, Design education, Design engineering, Prototyping

Contact:

Soomro, Sohail Ahmed

University of Oulu

Ubiquitous Computing

Finland

sohail.soomro@oulu.fi

Cite this article: Soomro, S. A., Barhoush, Y. A. M., Gong, Z., Kostakos, P., Georgiev, G. V. (2021) 'Tools for Recording Prototyping Activities and Quantifying Corresponding Documentation in the Early Stages of Product Development', in Proceedings of the International Conference on Engineering Design (ICED21), Gothenburg, Sweden, 16-20 August 2021. DOI:10.1017/pds.2021.577 


\section{INTRODUCTION}

Digital fabrication techniques spearheaded by maker movements and fabrication laboratories (FabLabs) (Barton et al., 2017; Georgiev, 2019; Gershenfeld, 2012; Ylioja et al., 2019), have changed the way we think, ideate, create, materialise, and interact with one another in our current data-driven society (Georgiev and Milara, 2018; Milara et al., 2017; Soomro et al., 2021). Numerous studies have sought to elucidate the different aspects involved in the prototyping processes in digital fabrication (Barhoush et al., 2019; Soomro \& Georgiev, 2020). Recent research has also sought to describe creativity in the context of making (Georgiev et al., 2016), highlighting the pivotal role of documenting digital fabrication projects 'while-doing' (Milara et al., 2019).

It is useful to understand why observing prototyping activity helps shape our understanding of the creating process. Prototyping is an important part of the product development (PD) process. 'A prototype is a pre-production representation of some aspect of a concept or final design' (Camburn et al., 2017, p.1). The early stages of the design can provide insight into the PD process. The data captured from the early stages of PD can help researchers understand how creativity and prototyping activities occur (Georgiev et al., 2017), which can improve the design itself. The literature on this topic presents several options for addressing this issue. One option is to use software, such as Design Rationale editor (DRed), in which each stage of PD is reported with the maximum possible detail (Bracewell et al., 2009). The conceptualisation and prototyping phases of any industrial PD are crucial, playing an important role in improving product design and efficiency before producing and launching the product into the market. Undoubtedly, documentation tools that capture maximum information from prototypes of physical artefacts can be very useful.

The aim of this study is to examine systems of documentation of physical prototypes reported in the literature and compare them to web-based blogging as a documentation tool. In the following sections, we classify, compare, and define the anatomy of such systems, providing information that may help researchers, academics, and designers implement more effective solutions for documenting prototyping activities.

To demonstrate how web-based blogging can facilitate the documentation of prototyping activity in educational settings, we conducted a study with eight teams of students who developed physical prototypes and reported their activity using a conventional web-based blog, without any automatic documentation tools. The study was conducted in the context of an academic course titled 'Principles of Digital Fabrication'. This case study illustrates the data produced and the advantages of using a blog for documentation of prototypes and provides an opportunity to compare blogs with other documentation tools described in the literature.

\section{LITERATURE REVIEW}

Several systems documenting the early stages of PD have been reported in the literature. Most systems end with a shared repository, where all the information is stored. In these systems, three types of data are captured: text, images, and videos. Furthermore, documentation tools are often composed of three parts: a sensor platform to capture input data, a repository to store the data, and a user interface for data retrieval, such as that presented by Kohtala et al. (2018). We reviewed several systems to develop a detailed understanding of their inner mechanics. Bracewell et al. (2009) emphasised the storage of information at each stage of the engineering design and PD. They proposed a software tool, DRed, to capture and store PD processes. The authors concluded that the stages of PD are not systematically documented in the industry, and that most of the steps taken are stored in the designer's memory, which causes problems related to information retrieval and future use of the data. Unlike Kohtala et al. (2018), they did not propose a hardware tool to capture prototype progress. Instead, they emphasised prototype information storage and retrieval.

In another study, Sjöman et al. (2017) proposed a systematic repository to store each stage of the prototype development data. The purpose of this system is to share the design output and process while making a prototype. The main concern of their study (Sjöman et al., 2017) was to have a well-organized and simple repository where all prototype information can be stored systematically. The information can be in the form of images with the details of the prototypes by stage. Such a repository is useful for both designers and researchers. The repository is also connected to hardware with a webcam to upload the pictures and metadata of the prototypes. Barhoush et al. (2019) described another system for capturing prototyping progress: Protobooth Oulu. In this system, the authors attempted to create an effortless tool 
to report prototype progress using a snapshot. They take a snapshot of the prototype at different stages and upload this data to a website or blog. The main motivation of the project is to have design education students record prototype progress without logging on to a website. The system takes pictures of the prototype and uploads them to the blog as a post. Kohtala et al. (2018) reported a prototype progress capturing system (Protobooth). Instead of producing a snapshot of the output (prototype), the authors suggest using more intensive hardware to collect data from the prototyping activity. Their version of Protobooth contains multiple cameras to perform a 3D scan, a camera to convert paper-based images to vector design files for laser cutters, and a video recording option. The data are uploaded to a repository. However, no option for design rationale is available in the system. Figure 1 summarises the advantages and limitations of each type of system identified in the literature. The classification mentioned in Figure 1 is further elaborated in the discussion section.

Web-based blogs are one of the simplest ways to document prototyping processes, as they do not require any specific hardware and/or software (Soomro and Georgiev, 2020; Wolf et al., 2014). Mobile phones can be used to take pictures and write blogs to store progress. In the following sections, we present a case study on Principles of Digital Fabrication course as an example of documenting the prototyping process using a blog.

\begin{tabular}{|c|c|c|c|c|c|}
\hline Classification & System Proposed & Technology & Advantages & Limitations & Target User \\
\hline Software & Bracewell et al., (2009) & $\begin{array}{l}\text { Computer-based software } \\
\text { application }\end{array}$ & $\begin{array}{l}\text { Well-designed software } \\
\text { for designers to store } \\
\text { and retrieve product } \\
\text { development information }\end{array}$ & $\begin{array}{l}\text { No mechanism to collect } \\
\text { information from the } \\
\text { design automatically }\end{array}$ & Industry \\
\hline Software & Adeegbe, J. M. (2019) & $\begin{array}{l}\text { Web-based software } \\
\text { application for managing, } \\
\text { storing, and analyzing } \\
\text { prototype data }\end{array}$ & $\begin{array}{l}\text { Remotely accessible data } \\
\text { analysis tool for research } \\
\text { and data retrieval }\end{array}$ & $\begin{array}{l}\text { User needs to upload } \\
\text { multimedia information } \\
\text { manually }\end{array}$ & Academics \\
\hline Hardware & Kohtala et al., (2019) & $\begin{array}{l}\text { Camera, LASER, video } \\
\text { recording, 3D scanning, } \\
\text { repository }\end{array}$ & $\begin{array}{l}\text { Fully integrated system } \\
\text { from data capture to } \\
\text { storage }\end{array}$ & $\begin{array}{l}\text { No specific feature for } \\
\text { information regarding the } \\
\text { design rationale }\end{array}$ & Researchers, designers \\
\hline Hardware & Barhoush et al., (2019) & $\begin{array}{l}\text { Camera, RFID (radio- } \\
\text { frequency identification) and } \\
\text { web-based } \\
\text { blog posts }\end{array}$ & $\begin{array}{l}\text { Portable, easy to } \\
\text { implement }\end{array}$ & $\begin{array}{l}\text { Captures only snapshots } \\
\text { of the prototype }\end{array}$ & Academics \\
\hline Hybrid & Sjöman et al., (2017) & $\begin{array}{l}\text { Camera and RFID } \\
\text { predesigned repository }\end{array}$ & $\begin{array}{l}\text { Well-organized system } \\
\text { for data storage and } \\
\text { retrieval }\end{array}$ & $\begin{array}{l}\text { Metadata related to } \\
\text { prototype }\end{array}$ & Designers, researchers \\
\hline Hybrid & Erichsen et al., (2020) & $\begin{array}{l}\text { Fully automatic system to } \\
\text { capture multimedia data and } \\
\text { store it in the repository }\end{array}$ & $\begin{array}{l}\text { AI-based predictors and } \\
\text { classifiers for design } \\
\text { analysis, metadata of } \\
\text { prototype }\end{array}$ & $\begin{array}{l}\text { Integration of systems } \\
\text { from different locations is } \\
\text { not tested. }\end{array}$ & Designers, researchers \\
\hline
\end{tabular}

Figure 1. Classification of the documentation tools for design and prototyping

\section{METHODOLOGY}

Web-based blogs are a common method used by academics to document prototyping activities (Wolf et al., 2014) (Soomro and Georgiev, 2020). To analyse how blogs can be a useful documentary tool, we conducted a study with MSc students, making prototypes in Principles of Digital Fabrication course.

\subsection{Case study: Principles of Digital Fabrication course}

The course examined in this case study did not use any prototype capturing tool, such as those mentioned in Figure 1. Therefore, our approach provides an opportunity to analyse students' reflections without using an automatic prototype capturing tool. The course offered, Principles of Digital Fabrication, was a seven-week course with an hour-long theoretical lecture and a two-hour workshop per week. Offered to MSc students, the course was designed to help students understand digital fabrication tools for making prototypes involving mechanical, electrical, and software tools. Access to the FabLab tool was intended to be provided to all students throughout the course; however, because of the COVID-19 pandemic, the lecture delivery and workshop mode were switched to remote learning. During the course, participants were asked to reflect on the workshops and on their final project progress weekly by posting on a WordPress blog. Participants could log in and create posts using a user-friendly graphical interface. Participants were supposed to discuss the final project in the first week and keep reporting on each stage of the prototype development, concluding the development 
process in week seven. Because of exceptional circumstances (COVID-19), extra time was provided to those who could not complete the project within seven weeks. Participants were asked to use the tag function provided by WordPress and label posts related to their final project using the tags 'idea', 'weekly development', and 'conclusion'. Using these tags, labelled data were collected to reflect the prototype development process and consistency of the participants.

\subsection{Case study results}

During the course, thirteen teams participated, and eight completed the project and its documentation. The projects are briefly introduced here. Only completed projects were considered in this study. To anonymise the students, project names are changed to $\mathrm{P} 1, \mathrm{P} 2$, and so on $(\mathrm{n}=8)$. P1 is a moving alarm clock, and to switch off the alarm, the user first needs to catch the clock. P2 is an electronic goose that honks when the noise level exceeds a certain threshold. P3 is a dustbin that opens when the user is nearby. P4 is a decibel meter which measures noise at a house party and indicates its level through an LED. P5 is a table-cleaning robot. P6 is an electronic alarm clock. P7 is a do-nothing box: if a button pressed, the box opens only to close itself again. P8 is a box representing a house that would play some music that can be silenced by knocking on the door.

\subsubsection{Consistency}

Consistency in documenting progress can help evolve prototypes, and information from the early stages of PD can help designers improve the design of prototype (Gutierrez et al., 2018). Despite being forced to switch to remote learning, course participants were found to be consistent in their reporting of prototyping activity. This is evident in the number of posts students made during the course (Figure 2). Figure 2 shows the total number of posts made on each day for all course weeks. Figure 3 shows the students creating posts vs. time trends, indicating student posting patterns even late at night.

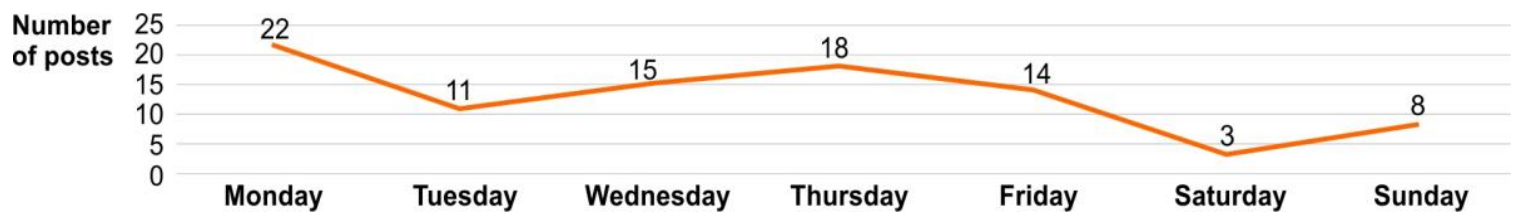

Figure 2. Post per day of the week. Y-axis shows the number of posts

During the course, lectures were delivered on Monday. For workshop, the students were divided into two groups: the first group workshop was held on Tuesday, and the second group workshop was held on Wednesday. In Figure 2, the high number of posts on Monday, Wednesday, and Thursday highlights the timely posting of reflections. The number of posts on Monday was the highest because students were supposed to post on the progress of their project within the same week. Therefore, students tended to post reflections just before the start of the next lecture. One possible interpretation of Figure 2 could be that the students were supposed to post their progress each week; therefore, it can be said that students were consistent because they had to post progress each week. Hence, we do not wish to argue the motivation of the students here; however, there is consistency in the student progress postings each week.

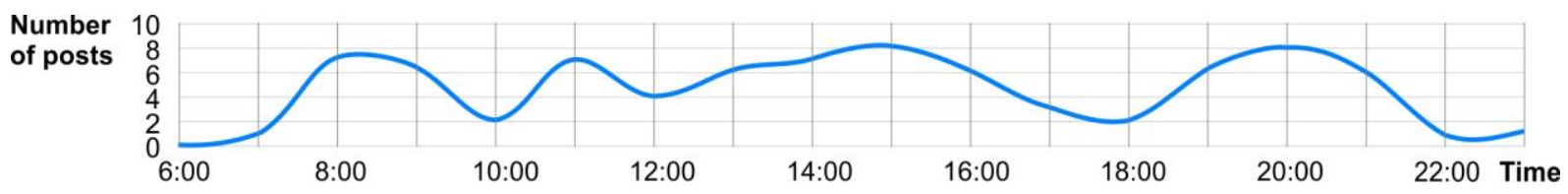

Figure 3. Post vs time of the day trend. Y-axis shows the number of posts

\subsubsection{Prototype development process}

The prototype development process can be observed by monitoring the progress of participants in their project over time. Eight teams came up with different projects. Each team had three to four members. Figure 4 shows the posts per project, which reflects how actively teams posted their prototype development progress. However, frequent posting is not necessarily a sign of quality, which is why we analyse the word count of each post of each project in the following word-count analysis section. 


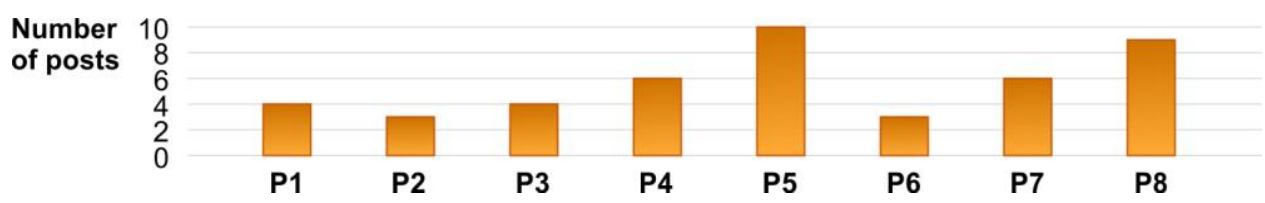

Figure 4. Number of posts per project. $Y$-axis shows the number of posts

The prototype development process is divided into three stages: design, weekly development, and conclusion. Students were asked to tag their documentation blog posts accordingly. Each group's first post was about the design phase. There was only one post in each group tagged as 'Design'. 'Weekly development' tag was used in the posts to indicate weekly process during all 7 weeks of the course, resulting in a maximum of seven posts per project. 'Conclusion' was the tag used for the final post in which the group reflected on the final prototype developed. Figure 5 shows the number of posts per stage of development throughout the course. Ideally, each completed project should have used an equal number of 'Design' and 'Conclusion' tags (one of each post was required per project). However, some of the projects were incomplete. Such incomplete projects were not considered in this study.

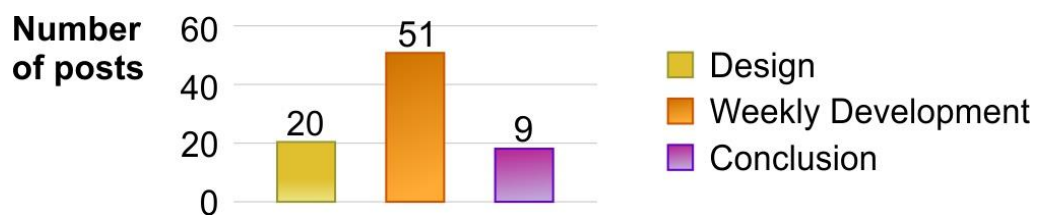

Figure 5. Prototype development categories.

\subsubsection{Group projects}

Two patterns emerged in the completion of projects: the first included teams that completed projects within the given time (by May 2020), and the second included teams that completed projects within an extended period (by August 2020). Because of the limited access to the FabLab facilities (due in part to the COVID-19 pandemic), extra time was granted to teams with incomplete projects. This trend can be observed in Figure 6, in which each bar shows the number of posts per project; it only presents the completed projects. The figure shows two projects, P5 and P8, which were posted in April and May. It shows that both project teams reported on their progress as they developed their prototype, which was a requirement for the group project. None of the remaining projects followed the documenting 'whiledoing' approach. A more alarming aspect is that the projects completed in August 2020 also started documentation in the same month. These delayed projects resulted in fewer posts on their weekly development progress. It can be concluded that the groups conceived an idea and implemented it within a few days (Figure 7). To conduct an in-depth analysis of each project, we next examined the development process.

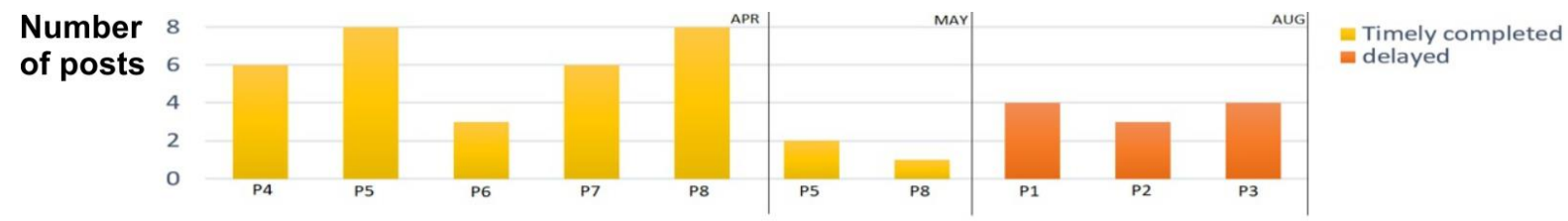

Figure 6. Project completion. Each bar shows number of posts per project.

The above results suggest that either students were documenting 'while-doing' their project or not documenting at all. Documenting while developing a prototype is important for maintaining the quality of the posts. This type of project reporting is useful for others, and there is little chance of information loss. In their posts, students recalled the issues they faced during that week and how they solved them. Figure 7 shows each phase of the project development with the time and number of posts made during each phase. The three projects completed in August had all three phases-idea, development, and prototype-which were all posted in the same month. This is considered to be the worst case. The best case was the P5 and P8 projects, which reported all stages of prototype development in a timely manner. 


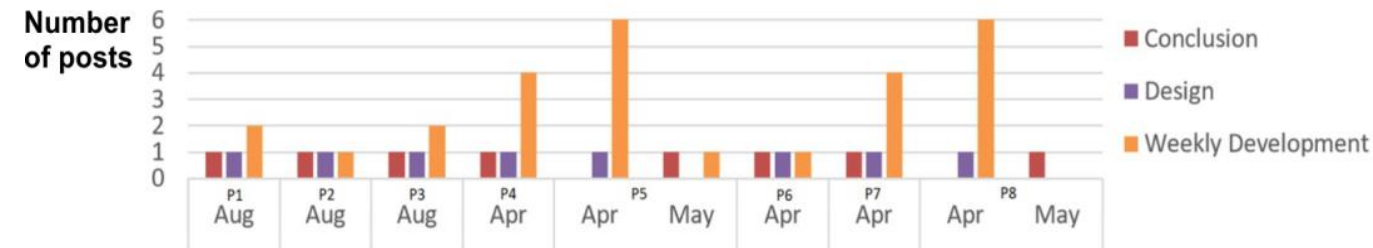

Figure 7. Group project categories. Shows number of posts in a development stage.

\subsubsection{Instructors}

Knowledge sharing through web blogs is beneficial not only for students but also for other stakeholders. During the course, instructors motivated the students to document their process, so that the students could reflect on all the problems they faced and report on how they solved each problem. Because of the significant amount of time required to document, students preferred to save documentation for the end of the project/task. However, during the remote learning period, it was not possible to provide the students with prototype capturing tools. In this case, blog posts were preferred by students and instructors.

The late posting of progress is also seen in Figure 7, which shows that not all teams posted their progress weekly; only two teams did so. This inconsistency makes it difficult for instructors to see students' progress. This can be a limitation of using blog posts for prototype development documentation, despite the ease of use. However, if posts are tagged properly by the students, then blogs can be a very useful tool for instructors to utilise process data for research purposes and help improve documentation for future courses.

\subsubsection{Word-count analysis}

The number of posts may not be a proxy for determining the quality of content. Process and experience should also be reported in a post so that the post can be helpful for other students, instructors, and researchers. One way to determine the level of detail of a post is to use the word count. The words were counted from posts using WordPress based Plugin. A reasonable way to do this is to determine the average number of words per post, not the number of words per project, because the number of posts in all projects is different. Figure 8 shows the average word count per post for all projects.

In Figure 9, we can see that groups that reported progress in a timely manner used more words per post. This means that their posts were much more detailed than those who completed their projects just at the end of the course. Considering this trend, we calculated the correlation between the number of posts and average word count per post. Projects with a higher number of posts had a higher average word count. Correlation coefficient is calculated between both variables using 'CORREL ()' function in MS Excel. The positive correlation coefficient was determined to be 0.619 ( $n=8)$. It shows a good to moderate relationship between both variables; however, further detailed content analysis (multimedia analysis) can help establish this relationship. As the scope of this study is limited to documentation tools, a detailed content analysis is suggested for future studies.

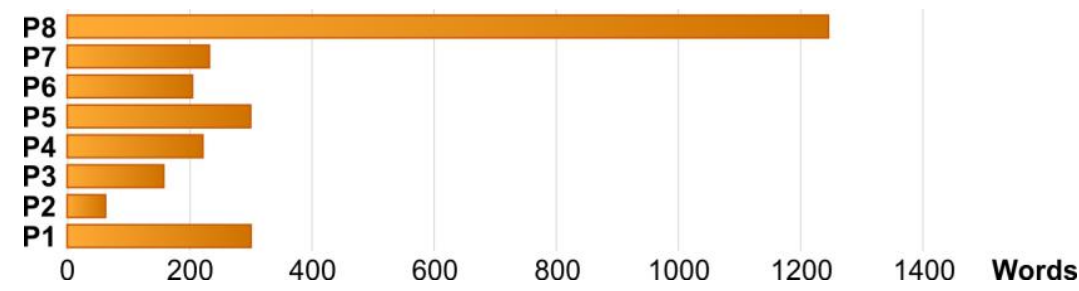

Figure 8. Average words per post of each project.

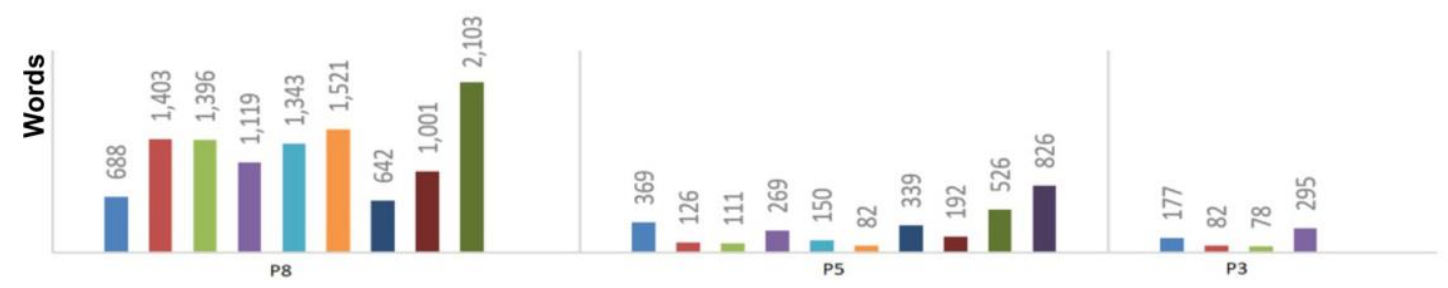

Figure 9. Words per post per project. Each bar represents words per post. 


\section{DIsCUSSION}

The case study presented above illustrates how blogs can be used to document prototyping activities in an academic course. Instructors' evaluation of the activity and the type of data that can be produced for research were also found to be useful. In this section, we compare a system that captures information from a prototype with and without automatic support. We then classify the system and discuss its anatomy and the targeted user.

\subsection{Blogs as a documentation tool}

Sharing information about a prototype development stage and reflections on this activity are important in design education. This information is valuable to students, instructors, and researchers. Blogs can be a useful tool for sharing such information. We have analysed in the case study results subsection how blogs can be used as documentation tools for sharing progress on prototype development, especially in the case of remote education. We also analysed the usefulness of this tool for student teams (group projects) and instructors. This tool also allows teams to see one another's documentation.

\subsection{Capturing prototype progress with and without autonomous systems}

In 2018, the Principles of Digital Fabrication courses were offered to a similar audience (MSc students). A study conducted during this course (Barhoush et al., 2019) described how students documented their progress using Protobooth Oulu (a prototype progress capturing tool). Access to digital fabrication tools was provided to students throughout the course. The students project in the case study presented in this research paper did not use Protobooth Oulu, which allows us to compare the two ways of documenting prototyping activity for design education.

\subsubsection{Accessibility}

In design education, information about prototyping activities can help improve PD. The first noticeable aspect that can be observed in the systems mentioned in Figure 1 and in the blog is accessibility. Usually, automatic tools used to capture prototyping progress are available in a laboratory; thus, students have to wait for their turn and adjust their schedule to its working hours. The use of such tools is difficult in the case of remote education. If remote education continues, we will lose the opportunity to capture useful information from the students' prototypes. In such a situation, documenting information via blog posts without using any prototyping capturing tools is more feasible. Figure 3 shows the rate of blog posts over a period of several hours exhibited in the case study discussed above. Blogs allow students the flexibility to post anytime it suits them, instead of waiting to access the prototyping capturing system in the laboratory. Access to information and digital fabrication tools has also been discussed in the literature (Boer, 2015).

\subsubsection{Data}

We can compare the number of captures/posts by each team throughout the course. In an earlier study conducted by (Barhoush et al., 2019), it was found that only three of the ten teams actively posted progress using Protobooth. In comparison, the present case study found that eight out of ten teams reported progress in all three stages of prototype development (idea, development, and conclusion) (see Figure 8). Therefore, more information on prototyping activity can be made available without the use of prototype capturing tools. Blogs also allow students to upload multimedia data and 2D and 3D animations and have no word limits, which helps generate more data and improves the understandability of the post. The disadvantage is that such types of blog posts require more space for storage.

\subsubsection{Information retrieval}

In the case of the blog-based documentation system, students were free to reflect and show their progress in their own style. Because of this freedom, useful information related to the design rationale can be difficult to retrieve. Conversely, a repository with tagging and logging features and a userfriendly interface (Bracewell et al., 2009) could make it easier to use the information for research and the PD process. 


\subsubsection{Co-creation}

Web-based blogs consist of posts that often act as conversations that connect students, instructors, and readers simultaneously. It creates contact between the maker, instructor, and other team members: they can read, comment, and participate. It helps in creating better designs and prototypes. The importance of co-creation was highlighted by Fleischmann et al. (2016).

\subsection{Classification}

Documentation systems can be divided into three classes based on their technology, architecture, and target users.

\subsubsection{Software-based prototype capturing tools}

Software-based systems designed to capture prototype information and design rationales are often used for industrial applications in engineering design. Many such applications have been discussed by Bracewell et al. (2009). These systems focus on design rationale and data retrieval. As discussed by Bracewell et al. (2009), most of the information regarding the changes made in design is stored in the memory of designers and engineers, which makes design and development more dependent on human experience. By storing each step of information design using software, such as DRed, engineering design becomes much more convenient. Software-based systems also consist of web-based applications that are used for less critical applications, such as education (Adeegbe, 2019).

\subsubsection{Hardware-based prototype capturing tools}

Hardware-based systems are designed to automate the process of capturing information from a prototype with little effort from the user (Barhoush et al., 2019). These systems conduct multiple transducers to capture information and store it in a repository. Image, video, 3D scans, and other types of tools are used for data collection (Kohtala et al., 2018). Such a system is helpful for users who are less interested in recording information while developing a product. It helps users scan prototypes with little to no effort.

\subsubsection{Hybrid tools}

A hybrid system is the integration of a well-designed design rationale software with an automatic prototype information capturing system. This type of system is ideal for all users, including designers, engineers, researchers, and students. One such system, which provides a user-friendly interface for scanning and a comprehensive graphical user interface (GUI) based repository for data retrieval and visualisation, was developed and tested by (Erichsen et al., 2020). The classifications of the systems are presented in Figure 1.

\subsection{Future system anatomy}

Apart from blog-based documentation, an extension of this research work is the implementation and performance analysis of a system that automatically captures information from a prototype. The feasibility and reason for each module of the system are based on its application and experimental endorsement from the literature (see Figure 1). A system with this anatomy can capture maximum information from prototypes and store it systematically in a central place (repository) using tagging, $\log$, and design rationale. Furthermore, it combines features of systems reported in the literature and proposes a modular implementation approach. As for the use of such systems, Erichsen et al. (2020), Barhoush et al. (2019), and Kohtala et al. (2018) worked on various aspects of such systems and used them to capture the prototyping process automatically in educational settings.

The future system anatomy is based on seven modules. (i) The first module is a mechanical module which is responsible for holding all information capturing tools and sensors required to obtain data from the prototype under observation. This module is based on different designs and materials. Kohtala et al. (2018), Barhoush et al. (2019), and Sjöman et al. (2017) implemented this module using plywood and metal sheets. (ii) The visualisation module (VM) is included in different ways in all the systems mentioned in Figure 1. The most common types of VM are touch LCD and mobile applications. This module helps the user interact with the system-capturing prototype. Using this module, the user can be asked questions regarding the design stage, which helps in generating qualitative information related to the prototype. The visualisation module can also be used to inform 
users of the system's status (e.g. what the system is currently doing). (iii) The analytical module can be defined as software embedded in hardware that pre-processes information and makes on-site decisions. This module does not have to be on the site where the prototype is being observed; it can be implemented on the server where the information is sent. The analytical module is based on AI (Artificial Intelligence) algorithms that make decisions, such as the type of materials used in the prototype (Erichsen et al., 2020). Raspberry pie and a similar microcontroller-based system were used in the systems mentioned in Figure 1 to control and analyse information on-site. (iv) The communication module is responsible for communicating information between the on-site system and the repository. Most of the automated systems mentioned in Figure 1 use a Wi-Fi module to communicate information (Barhoush et al., 2019; Sjöman et al., 2017). Other technologies, such as Zigbee and Ethernet, can also be used, depending on the topology and bandwidth required for communication. (v) The orchestration module is responsible for the coordination between multiple types of prototype capturing systems present at different sites. This module is helpful in scaling up the overall system, which will create opportunities for collecting more data from multiple sites, and this helps improve the accuracy of the AI-based system (Erichsen et al., 2020). Unlike APIs, orchestration should be able to handle all types of data and normalise it into a single standard. (vi) The repository is a backend system in which information is stored. It is usually a cloud server with web access (Erichsen et al., 2020). In the case of software-based tools, the repository stores the information regarding design rationale (Bracewell et al., 2009). Repositories will remain a pivotal place even in future systems that may have more advanced software features and hardware that automatically capture information. (vii) The GUI module provides access to repositories. In the system proposed by Erichsen et al. (2020), the GUI module is a web-based user interface that provides access to the repository which can be considered as one of the best interfaces among all the systems reviewed (see Figure 1) in this study. Kohtala et al. (2018) used a well-organized application to store information. Figure 10 shows each module of the system described above.

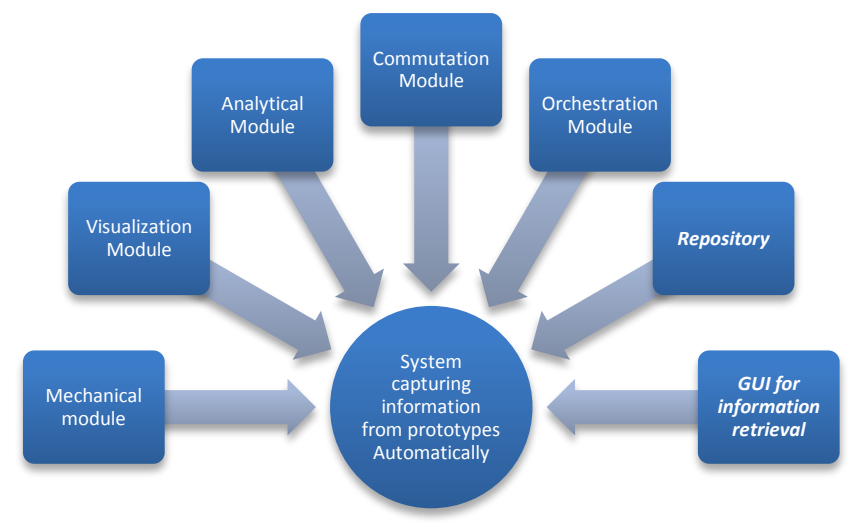

Figure 10. Future system anatomy.

\section{CONCLUSION}

In this study, we compared different tools that help documentation of prototyping activities related to physical artefacts. We identified three types of such tools. First, software-based tools are connected to a software application that stores, manages, and retrieves data regarding the design and prototyping process of an engineering design or product. Second, hardware-based tools use hardware that automatically captures information from prototypes with little user intervention. Third, hybrid systems are the integration of the first two types. The advantages and limitations of all types of systems were presented. We also presented a case study of a web-based blog system used to document prototypes in an educational setting. This study illustrates how this system could be beneficial in different situations. This study also demonstrated the possible data that could be collected from a blog-based repository for future research. Finally, the anatomy of such a future system was defined based on the tools available in the literature. This research is helpful for researchers interested in developing tools for capturing, storing, managing, and analysing information from the early stages of PD. The system anatomy provided along with a summary of available tools can help engineers develop optimal tools to capture prototyping activities. 


\section{ACKNOWLEDGEMENT}

This study has been financially supported by Academy of Finland 6Genesis Flagship (grant 318927).

\section{REFERENCES}

Adeegbe, J. M. (2019). A System Supporting Analysis of Prototyping in Fab Lab Education (Master's thesis). University of Oulu, Finland

Barhoush, Y.A.M., Erichsen, J.F., Sjöman, H., Georgiev, G.V., Steinert, M., 2019. Capturing Prototype Progress in Digital Fabrication Education, in: Proceedings of the Design Society: International Conference on Engineering Design. Cambridge University Press, Delft, The Netherlands, pp. 469-478. https://doi.org/10.1017/dsi.2019.50

Barton, A.C., Tan, E., Greenberg, D., 2017. The Makerspace Movement: Sites of Possibilities for Equitable Opportunities to Engage Underrepresented Youth in STEM. Teach. Coll. Rec. 119, 060308.

Boer, J. de, 2015. The business case of FryskLab, Europe's first mobile library FabLab. Libr. Hi Tech 33, 505518. https://doi.org/10.1108/LHT-06-2015-0059

Bracewell, R., Wallace, K., Moss, M., Knott, D., 2009. Capturing design rationale. Comput.-Aided Des. 41(3), 173-186. https://doi.org/10.1016/j.cad.2008.10.005

Camburn, B., Viswanathan, V., Linsey, J., Anderson, D., Jensen, D., Crawford, R., Otto, K., Wood, K., 2017. Design prototyping methods: State of the art in strategies, techniques, and guidelines. Des. Sci. 3. https://doi.org/10.1017/dsj.2017.10

Erichsen, J.F., Sjöman, H., Steinert, M., Welo, T., 2020. Digitally Capturing Physical Prototypes During Early-Stage Engineering Design Projects for Initial Analysis of Project Output and Progression. ArXiv190501950 Cs.

Fleischmann, K., Hielscher, S., Merritt, T., 2016. Making things in Fab Labs: a case study on sustainability and co-creation. Digit. Creat. 27, 113-131. https://doi.org/10/gfc7vp

Georgiev, G.V., 2019. Meanings in Digital Fabrication, in: Proceedings of the FabLearn Europe 2019 Conference, FabLearn Europe '19. Association for Computing Machinery, New York, NY, USA, pp. 1-3. https://doi.org/10.1145/3335055.3335073

Georgiev, G.V., Milara, I.S., 2018. Idea generation challenges in digital fabrication, in: Proceedings of the Fifth International Conference on Design Creativity (ICDC 2018). University of Bath, Bath, UK, pp. 85-92.

Georgiev, G.V., Milara, I.S., Ferreira, D., 2017. A Framework for Capturing Creativity in Digital Fabrication. Des. J. 20 (sup1), S3659-S3668. https://doi.org/10.1080/14606925.2017.1352870

Georgiev, G.V., Oja, M., Sánchez, I., Pyykkönen, M., Leppänen, T., Ylioja, J., van Berkel, N., Riekki, J., 2016. Assessment of relatedness to a given solution in 3D fabrication and prototyping education, in: Proceedings of the Fourth International Conference on Design Creativity (ICDC 2016). Atlanta, USA, pp. 02-04.

Gershenfeld, N., 2012. How to make almost anything: The digital fabrication revolution. Foreign Affairs 91(6), 43-57.

Gutierrez, M., Ruiz, G., Luyten, K., Haesen, M., Coninx, K., 2018. Re-thinking Traceability: A Prototype to Record and Revisit the Evolution of Design Artefacts, in: ACM Conference on Supporting Groupwork. pp. 196-208. https://doi.org/10.1145/3148330.3148334

Kohtala, S.M.I., Erichsen, J.A.B., Sjöman, H., Steinert, M., 2018. Augmenting Physical Prototype Activities in Early-Stage Product Development, in: DS 91: Proceedings of NordDesign 2018. Linköping, Sweden.

Milara, I.S., Georgiev, G.V., Riekki, J., Ylioja, J., Pyykkönen, M., 2017. Human and Technological Dimensions of Making in FabLab. Des. J. 20, S1080-S1092. https://doi.org/10.1080/14606925.2017.1353052

Milara, I.S., Georgiev, G.V., Ylioja, J., Özüduru, O., Riekki, J., 2019. “Document-while-doing”: a documentation tool for Fab Lab environments. Des. J. 22, 2019-2030. https://doi.org/10.1080/14606925.2019.1594926

Sjöman, H., Erichsen, J., Welo, T., Steinert, M., 2017. Effortless Capture of Design Output - A Prerequisite for Building a Design Repository with Quantified Design Output, in: International Conference on Engineering, Technology and Innovation (ICE/ITMC). IEEE, 567-570. https://doi.org/10.1109/ICE.2017.8279935

Soomro, S.A., Casakin, H., Georgiev, G.V., 2021. Sustainable Design and Prototyping Using Digital Fabrication Tools for Education. Sustainability 13, 1196. https://doi.org/10.3390/su13031196

Soomro, S.A., Georgiev, G.V., 2020. A Framework to Analyse Digital Fabrication Projects: The Role Of Design Creativity, in: Design Society (ICDC 2020). Presented at the Proceedings of the Sixth International Conference on Design Creativity, Oulu, Finland. https://doi.org/10.35199/ICDC.2020.46

Wolf, P., Troxler, P., Kocher, P.-Y., Harboe, J., Gaudenz, U., 2014. Sharing is sparing: open knowledge sharing in Fab Labs. J. Peer Prod. 5, 1-11.

Ylioja, J., Georgiev, G.V., Sánchez, I., Riekki, J., 2019. Academic Recognition of Fab Academy, in: Proceedings of the FabLearn Europe 2019 Conference - FabLearn Europe '19. ACM Press, Oulu, Finland, pp. 1-7. https://doi.org/10.1145/3335055.3335056 